\title{
Tsafon
}

Revue d'études juives du Nord

$72 \mid 2016$

Juifs, Israéliens, dans la littérature française et israélienne

\section{Élie Wiesel : une grande Voix s'est tue}

Michaël de Saint-Cheron

\section{(2) OpenEdition \\ Journals}

Édition électronique

URL : https://journals.openedition.org/tsafon/374

DOI : $10.4000 /$ tsafon. 374

ISSN : 2609-6420

Éditeur

Association Jean-Marie Delmaire

Édition imprimée

Date de publication : 1 décembre 2016

Pagination : 149-152

ISSN : 1149-6630

\section{Référence électronique}

Michaël de Saint-Cheron, «Élie Wiesel : une grande Voix s'est tue », Tsafon [En ligne], 72 | 2016, mis en ligne le 31 mai 2018, consulté le 06 juillet 2021. URL : http://journals.openedition.org/tsafon/374 ; DOI : https://doi.org/10.4000/tsafon.374 


\title{
Hommage
}

\section{Élie Wiesel : une grande Voix s'est tue}

\section{Michaël de Saint-Cheron*}

Avant de prononcer sa conférence Nobel, au lendemain de la réception de son prix Nobel de la paix (1986, Oslo), Wiesel trouva tout naturel de se prêter à ce qui a pu paraître une digression, mais qui en vérité était le cœur de ce qu'il avait à dire : il chanta.

L'un des témoins de cette soirée était Bernard-Henri Lévy, son éditeur, à l'époque. Ses lignes laissent passer une émotion. C'est que le médiatique philosophe reconnaît le charisme si pur qui caractérise Wiesel.

\begin{abstract}
A-t-on jamais entendu un lauréat du Prix Nobel de la Paix psalmodier en hébreu son discours de réception? [...] On ne l'a probablement même jamais imaginé. Mais la voix est si belle, la mélodie si prenante, la mélancolie qui se dégage de cet homme est soudain si pathétique que tout ce joli monde, le premier instant d'hésitation passé, finit par se mettre au diapason; et c'est toute la salle, tout le grand amphithéâtre légendaire de l'université d'Oslo qui, emporté par le chef d'orchestre improvisé, se met à reprendre en chœur le refrain du chant wieselien. ${ }^{1}$
\end{abstract}

Si Élie Wiesel parlait si souvent, n'est-ce pas pour protéger ce chant qu'il portait en lui, et qui fut sa part la plus pure, la plus secrète? De même, s'il écrit, c'est parce qu'il n'est pas devenu musicien. Il a cependant partagé à certains moments avec des amis ou le public d'un soir, sa passion du chant. C'est aussi pourquoi il écrivit sa cantate Ani

\footnotetext{
* École Pratique des Hautes Études, spécialiste reconnu de l'œuvre d'Élie Wiesel.

${ }^{1}$ Random House, New York, 1973.
} 
Maamin, un chant perdu et retrouvé, dont il confia la partition à Darius Milhaud, qu'il considérait si justement comme l'un des musiciens majeurs de notre époque - celui qui avait aussi une âme juive véritable. Plus qu'une cantate Ani Maamin est " une véritable Passion », comme l'écrit Paul Méfano, qui créa l'œuvre en France - 19 ans après la création mondiale à New York - à la salle Pleyel, le dimanche 15 novembre 1992, dans le cadre d'un concert de gala donné au profit de la Fondation pour la Mémoire de la Déportation, mais en l'absence de Wiesel. Cette œuvre a donc tout d'une «Passion d'Israël », mais le procès qui y est joué n'est pas le procès d'un homme, mais le procès de Dieu qui a laissé si souvent exterminer son peuple. Procès de Dieu qui conduit les patriarches de son peuple premier né - son peuple Messie - qui fut persécuté et mourut dans l'abandon total, dans la déréliction totale.

On a beaucoup comparé l'œuvre de Wiesel au Livre de Job. Sa cantate Ani Maamin en est peut-être l'expression la plus concise après $L a$ Nuit, assurément son grand livre.

Rarement sans doute un écrivain aura autant parlé de lui-même qu'Élie Wiesel à travers ses fragments de Mémoires, de Journaux, ses récits plus ou moins autobiographiques, ses entretiens, ses films, si ce n'est Flaubert, Julien Green et Marguerite Duras. Mais quelque chose de proustien est également palpable chez lui. Sans doute cet élément est-il déterminé par le sentiment d'Élie Wiesel selon lequel jamais on ne connaîtra ce qu'il a traversé d'abîmes. Si donc jamais on ne saura, trop est encore pas assez pour raconter le temps disparu et dans son cas la mort de son peuple. Dire que l'âme de son œuvre est la mémoire de sa tragédie personnelle serait une banalité s'il ne s'était fait lui-même l'architecte et le gardien de la mémoire de la Shoah dans son universalité. Ce qu'il a bâti est un Mémorial en l'honneur des disparus. Mais comme tout témoin au double sens du mot, celui qui a vu et celui qui porte témoignage, Wiesel a pu éprouver une fascination particulière pour le Messager éponyme du récit de Kafka. Il en donna un jour cinq niveaux de lectures, chaque fois plus resserrés.

Le personnage le plus tragique de Kafka, c'est celui qui n'arrive pas à délivrer son message. En relisant le texte, je me suis dit: il y a quand même quelque 
chose de pire. Ce qui est pire, c'est que le messager ne sache plus à qui il doit remettre le message. J'ai relu le récit une troisième fois et me suis demandé : qu'est-ce qui est pire ? C'est que le messager oublie le message. Est-ce tout ? Non, ce n'est pas tout : c'est quand le messager ne se souvient plus qu'il porte un message. Est-ce la fin ? Non, la fin, c'est lorsque le messager oublie de qui il porte le message. $^{2}$

Quelques années plus tard, Élie Wiesel approfondit encore sa réflexion et a donc conclu provisoirement que le pire c'est lorsque le message n'est pas reçu. Autrement dit lorsque le messager a laissé les auditeurs indifférents. Mais cette sixième lecture n'est pas l'ultime. Nous pourrions ajouter pour notre part: l'échec le plus grave, c'est lorsque le message est détourné, dévoyé, trahi de son sens.

Premier écrivain à être lauréat du prix Nobel de la paix, Élie Wiesel incarna à partir des années 1970, et plus encore depuis ces trois dernières décennies, une sorte de sage, de juste présent sur de nombreux fronts, et l'on s'étonnait qu'il puisse parfois prôner la guerre comme pour l'Irak suivant la politique américaine. Mais Élie Wiesel n'échappa pas aux ambiguiités de celui qui entend jouer un rôle public, et qui d'une certaine manière y est tenu de par son statut, ses fonctions officielles, sa notoriété. L'homme et ses contradictions n'éclipsèrent pas l'œuvre et a contrario celle-ci n'éclipse pas l'homme. Comme tout écrivain dont le rôle public est important, Élie Wiesel, au travers de son oeuvre, soulève des questions non résolues, des amphibologies inhérentes au personnage qui fut le sien et à sa célébrité. Il écrit par exemple dans ...Et la mer n'est pas remplie ces lignes un peu détonantes, que l'on ne s'attend pas à trouver chez lui, à propos des facilités matérielles que procure le Nobel :

\footnotetext{
Voyage en première classe ou sur Concorde. Hôtels luxueux. Honoraires à l'avenant. Fêté mais accaparé, vous n'êtes plus libre de vos mouvements. Couronné pour votre action ou pour votre œuvre, vous n'avez plus le temps de les poursuivre.
}

Tout en déniant devant moi toute idée de revanche, son attachement à ces détails épicuriens, nous font comprendre que celui qui entre dans le jeu n'est plus tout à fait libre. Certains prix Nobel de la paix - mais pas seulement de la paix ! - ont d'ailleurs toujours refusé de jouer ce jeu. Wiesel, lui, aimait « jouer » son rôle.

\footnotetext{
${ }^{2}$ Conférence donnée à la Fnac Montparnasse, à Paris, le 5 septembre 1989.
} 
Aujourd'hui, au lendemain de sa mort qui nous étreignit peut-être même davantage que ce à quoi nous nous attendions, un vide immense est laissé par la disparition de sa voix si frêle, si volontaire, dont l'aura incandescente la rendait unique entre toutes. Il nous reste son œuvre avec ce chant intérieur qui nous habitera longtemps encore. Pourtant la question n'est pas à propos de nous qui l'aurons entendu, connu, lu de son vivant, mais elle est toute entière pour les jeunes générations qui ne l'auront qu'à peine entendu puis ceux qui viendront après. Comme professeur, comme écrivain reçu dans de fort nombreuses universités, il a pu parler à des milliers de jeunes et je ne doute pas que son empreinte sera durable chez l'un ou l'autre d'entre eux.

En avril 2009, il fut reçu avec Simone Veil, au Centre universitaire de la Méditerranée (CUM), à Nice, pour parler à une centaine de jeunes lycéens, collégiens. Il conclut son intervention par ses mots qui résonnent toujours en moi avec autant de force :

Vous les jeunes, je vous dirai quelque chose : Accrochez-vous aux questions, car les questions unissent les hommes. Il n'y a que les réponses qui les divisent.

Cet humble fils de commerçants d'un shtetl des Carpates devenu écrivain, professeur d'université, docteur honoris causa d'au moins deux cents universités, prix Nobel de la paix, interlocuteur « des grands de ce monde ", n'a jamais oublié d'où il venait ni bien sûr ce à quoi il a dû son destin incroyable. Sa vie est un exemple de volonté, d'intelligence, portées par son charisme et par la chance.

D’Élie Wiesel, il nous reste une part de la mémoire, ses livres et plus encore, je le redis, ce chant qui traverse toute sa vie, toute son œuvre. 